\section{On manels and manferences in urology}

\author{
Imogen Patterson and Sigrid V. Carlsson
}

Balancing diversity on panels at academic medical conferences demonstrates a commitment to the principles of diversity and inclusion. However, it seems we have a long way to go in urology, where two-thirds of sessions at major urology meetings still consist of all-male speaker panels.

Refers to Teoh, J. Y.-C. et al. A quantitative analysis investigating the prevalence of "manels" in major urology meetings. Eur. Urol. https://doi.org/10.1016/j.eururo.2021.05.031 (2021).

Urology remains an overwhelmingly male specialty, but the proportion of female urologists is increasing. According to data from the 2020 American Urological Association census, for the first time in history, women urologists have now surpassed $10 \%$ of the urology workforce in the USA ${ }^{1}$. In addition, many academics devoted to urological research are women. However, the increasing female urology workforce is not necessarily reflected in the speakers and panels at academic urology meetings. In a recent study in European Urology, Teoh and colleagues ${ }^{2}$ investigated the prevalence of 'manels' - the name given to an all-male speaking panel - at urological meetings organized by major urological associations and societies over a single year between December 2019 and November 2020. Of 285 urology meeting sessions during that 1 -year period, almost two-thirds (64\%) were manel sessions. One could argue that inclusion on panels should be based on experience and merits and some amongst the meeting organizers or attendees might believe that participants with those qualifications are more likely to be older, more senior men. However, intriguingly, comparison of male faculty and their female counterparts with similar academic merits, taking into account metrics such as number of publications or H-index, showed that men still participated in more sessions than women in the urological meetings. Simply put: regardless of expertise and merit, men received more opportunities than women ${ }^{2}$.

Women are under-represented in urology and at urology meetings, and the fact that this disparity remains an issue in 2021 is vexing. Lack of gender diversity among panellists sends the wrong message to conference attendees and limits the perspectives shared with the audience to those of the men on the panel ${ }^{3}$, which might be disparate and detached from what the audience might experience. However, perhaps more importantly, in academic settings, in which national and international recognition and the opportunity to appear at a plenary session or present as an invited speaker counts towards promotion, it could be argued that manels are another form of career discrimination. Dr Francis Collins, Director of the National Institutes of Health (NIH), alluded to this issue in a 2019 statement declaring that he will no longer accept invitations to participate in manels ${ }^{4}$. This attitude has been echoed by many other men on an individual level, within urology and across other professions.
Manels and manferences ${ }^{5}$ - conferences largely dominated by male speakers - are not limited to urology or even academic medicine in general; other specialties and professions have come to the same conclusion about the persistence of this imbalance in their specialty conferences, as Teoh et al. ${ }^{2}$ rightly point out. The financial industry has reported similar findings, but here the burgeoning evidence demonstrates that gender diversity on boards or amongst startup founders leads to improved company performance ${ }^{6-8}$. A 2018 Boston Consulting Group report found that diverse leadership leads to improved innovation $^{6}$, and a Harvard Business Review study revealed that firms with more women in senior positions are more profitable than those without ${ }^{7}$. This evidence has led to improvements in recruitment and promotion of women within many companies to improve shareholder returns and stock market performance ${ }^{8}$. Taking into account these data illustrating the benefits of gender diversity, it is, therefore, perplexing that the failure to include or promote women in urology conferences and panels continues.

Many explanations have been proposed for the lack of female representation on speaker panels at conferences with traditionally lower proportions of women. To inject some humour into the debate, public health specialist Dr Mary E. Black created a 25-square 'manel bingo card' covering common excuses and misperceptions used to 'justify' excluding women from conference panels. These unfounded excuses include "there aren't enough qualified female speakers", "you can't kick out a male speaker just to fit a woman in there" and "all the women were probably

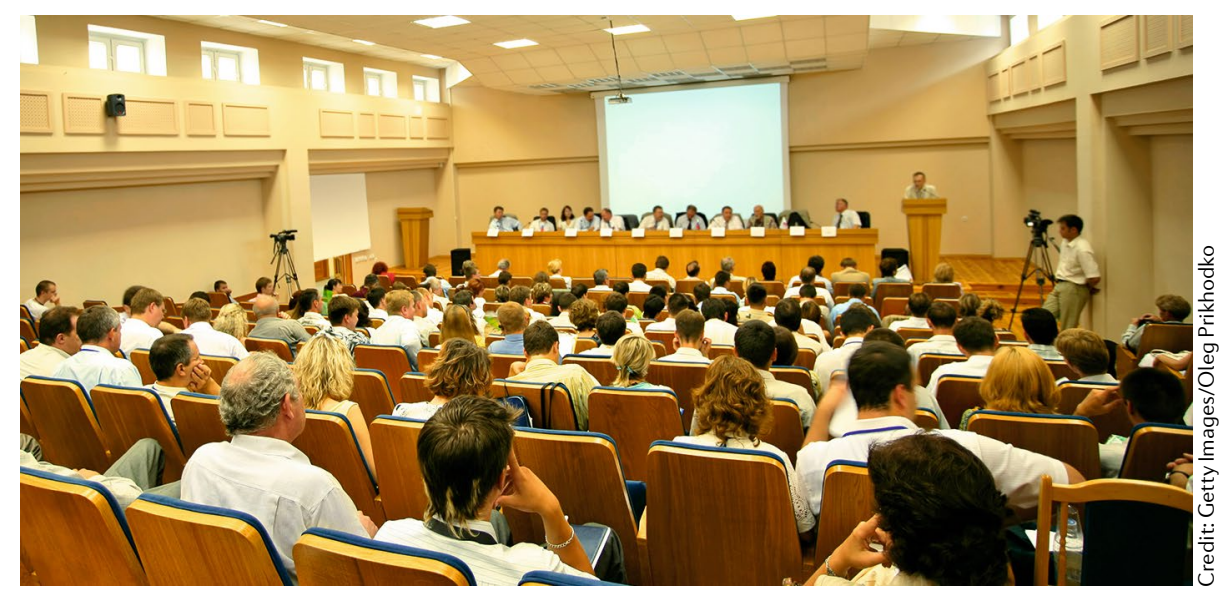


busy". The COVID-19 pandemic has further eroded the list of potential excuses for including women, as many meetings now have a virtual component. Video teleconferencing can obviate the need for every panellist to travel, thereby removing another tired excuse that women prefer not to travel because of family commitments - not to mention the fact that many men have families too. The rapid adoption of video teleconferencing during the pandemic has demonstrated the capability of urologists to expedite change and do away with eons of 'tradition' when necessary, making it even more unfortunate that manels have persisted for so long in our field despite the evidence that shows that the majority of urologists are able to accept change when it is forced upon us.

\section{To promote positive change, we must work together as organizers, panellists and audiences}

So, what can we all do to raise awareness of the problem of under-representation of women at academic medical conferences? Much like the declaration by NIH Director Collins ${ }^{4}$, or the recent diversity statement and commitment to change by the Royal College of Surgeons of England, which set gender diversity on panels as a measurable goal for inclusions ${ }^{10}$, this change requires a concerted effort by individuals and institutions to be proactive about inclusion. Committing to gender equity, amongst other diversity initiatives, is something each urological society should formalize. Conference organizers bear the greatest responsibility, as diversity begets more diversity ${ }^{3}$. The recent annual scientific congress for the Royal Australasian College of Surgeons, and in particular the Urological Society of Australia and New Zealand (USANZ) faculty, was an excellent example of how presenting a conference with speakers from diverse backgrounds in terms of gender, nationality, race, ethnicity and practice background can be done if there is a focus on change. At this meeting, the convenor, Professor Henry Woo, made a concerted effort to include a woman on every panel and for each panel to be representative of ethnicity, gender, and time in and location of clinical practice. Teoh et al. ${ }^{2}$ also point out the power of social media to create change and also mention the creation of searchable databases of qualified women speakers, such as the Society of Women in Urology Speaker Database.

To promote positive change, we must work together as organizers, panellists and audiences. Dr Black has written a simple guide for how to avoid manels, explaining the implicit bias that occurs in designing conferences and organizing panels ${ }^{9}$. She reminds conference planners to be mindful about the speaker line-up and to avoid inviting the usual suspects'. She also encourages men invited to sit on a manel to ask themselves the question 'Does it really have to be me?' and urges the audience to ask the question 'Are there really no women who know about this topic'? Dr Collins of the NIH is leading by example: in 'Time to end the manel tradition', he states "The diversity of bright and talented minds engaged in biomedical research has come a long way - and our public engagements need to catch up. Breaking up the subtle (and sometimes not so subtle) bias that is preventing women and other groups underrepresented in science from achieving their rightful place in scientific leadership must begin at the top"

\footnotetext{
Imogen Patterson ${ }^{\circledR}$ and Sigrid V. Carlsson ${ }^{2,3,4}$

'Department of Urology, Sydney Adventist Hospital, Sydney, New South Wales, Australia.

${ }^{2}$ Department of Surgery (Urology Service), Memorial Sloan Kettering Cancer Center, New York, NY, USA
}

${ }^{3}$ Department of Epidemiology and Biostatistics, Memorial Sloan Kettering Cancer Center, New York, NY, USA.

${ }^{4}$ Department of Urology, Institute of Clinical Sciences, Sahlgrenska Academy, University of Gothenburg. Gothenburg, Sweden.

凶e-mail:drpatterson@prescribepm.com.au https://doi.org/10.1038/s41585-021-00508-7

1. American Urological Association. 2020: The State of Urology Workforce and Practice in the United States (AUA, 2020).

2. Teoh, J. Y.-C. et al. A quantitative analysis investigating the prevalence of "manels" in major urology meetings. Eur. Urol. https://doi.org/10.1016/j.eururo.2021. 05.031 (2021).

3. Kibbe, M. R. \& Kapadia, M. R. Underrepresentation of women at academic medical conferences "manels" must stop. JAMA Netw. Open 3, e2018676 (2020).

4. Collins, F. S. Time to end the manel tradition. NIH https://www.nih.gov/about-nih/who-we-are/nih-director/ statements/time-end-manel-tradition (2019).

5. Else, H. How to banish manels and manferences from scientific meetings. Nature 573, 184-186 (2019).

6. Lorenzo, R., Voigt, N., Tsusaka, M., Krentz, M. \& Abouzahr, K. How diverse leadership teams boost innovation. Boston Consulting Group https://www.bcg. com/publications/2018/how-diverse-leadership-teamsboost-innovation (2018).

7. Noland, M. \& Moran, T. Study: firms with more women in the c-suite are more profitable. Harvard Business Review https://hbr.org/2016/02/study-firmswith-more-women-in-the-c-suite-are-more-profitable (2016).

8. Nguyen, H. \& Faff, R. Impact of board size and board diversity on firm value: Australian evidence. Corporate Ownership \& Control 4, 24-32 (2007).

9. Black, M. E. Mary E Black: "Manels" and what to do about them. BMJ Opinion https://blogs.bmj.com/ bmj/2018/1 2/07/mary-e-black-manels-and-what-todo-about-them/ (2018)

10. Royal College of Surgeons of England. The Royal College - our professional home. An independent review on diversity and inclusion for the Royal College of Surgeons of England. Royal College of Surgeons of England https://www.rcseng.ac.uk/ about-the-rcs/about-our-mission/diversity-review-2021/ (2021).

Acknowledgements

S.V.C. is supported in part by funding from the National Institutes of Health/National Cancer Institute (P30-CA008748 and K22-CA234400).

\section{Competing interests}

The authors declare no competing interests.

RELATED LINKS

Society of Women in Urology Speaker Database:

https://swiu.org/resources/speaker-db.aspx 